\title{
Energy Analysis of High Rise Building Integrated with BIM
}

Kuldeep Mishra and Amit Goel

\author{
Department of Civil Engineering, Chandigarh University, Gharuan, Mohali - 140413, Punjab, India; \\ kuldeepmi94@gmail.com, amitgoel.civil@cumail.in
}

\begin{abstract}
Objectives: This study considers three different architectural shapes of High rise building with reference to energy efficiency (solar), area and maximum occupancy at the same location. Methods/Statistical Analysis: It involves best shape identification, then finding best orientation, and considers the eight different directions including for the front side of the building (having an opening for sunlight and sun path up to six months). For the best orientation, few major cities in Indiaviz.Chandigarh, Chennai, Kolkata, Jaipur and Bhopal for their suitability. This study involves utilizing Building models made in Revit and transfer to Green Building Studio (GBS) for advance analysis. Autodesk Revit has a few Building Performance Analysis (BPA) features so as to analyse a 100 metre tall structure with 25 floor building. This provides more detailed look at the essentials requirements of running an energy simulation from within Revit. This will incorporate an introduction to the new 3D energy determine in Revit 2017, the programmed zoning highlight in Revit 2017. Findings: By using different model, shapes are developed with the running an energy simulations in Revit and Green building studio. Different Type settings were attempted on the construct and display and with respect to the Energy simulation model to get the most effective and economical use of space, renewable energy and most preferable orientation and percentage of glazing and opening ratio of the building that leads to energy analysis. Applications: As the limitation of space and energy demand is increasing in India, pre-estimate of the resources requirement for high rise structure is important considering solar and weather condition of specific terrain.
\end{abstract}

Keywords: Building Performance Analysis (BPA), Cost, Insight-A360, Energy, Location, 3D-BIM

\section{Introduction}

Expanding rate of urbanization in late decades has seen an accelerated development of high rise building around the world. Presently, tall and thin structures are needed for huge urban areas where space is constrained. Additionally, Sustainable buildingsdemand technique towards planning the working structures with the aim of utilizing energy and resources economically and these models deliver huge measure of information. Although whether it is in the choice of the flat load-restricting structure or the impact of bend on the structure, and against earthquake impacts or in the approach for planning the structure in the general geometry and outline of the building, the decisions made by the fundamental planner significantly influence the cost, constructability, and sensibility of tall structures.

$\mathrm{In}^{1}$ revealed that Building-Integrated Photo-Voltaics (BIPV) are cheaper compared to other approaches to store sunlight based power, which is the most infinite, limitless and clean of all the accessible energy assets. It examined issues concerning BIPV in structural plan in China, including how to preference among BIPV and Building Attached Photo-Voltaics (BAPV), irrespective of whether it is important for photovoltaic parts to keep going as long as building structures serviceability and how to plan BIPV structures. $\mathrm{In}^{2}$ analysed the energy consumption features of university dormitory. $\operatorname{In}^{3}$ discussed about the requirement for IFC 
(Industry Foundation Classes) and Building Information Modeling (BIM)-based examination of existing structures. A relative investigation of Building Energy Performance Analysis of an academic building provided a point by point discussion on different interventions incorporated to adjust the model. The study reasons that BIM/IFC based methodologies give another option to lead energy investigation of existing structures gave different connections are incorporated with the model. $\mathrm{In}^{4}$ seismic behaviour of Different Bracing Systems in High Rise steel structure with various sorts of edge was taken into examination for their behaviour. Nonlinear static pushover examinations were done to study the basic execution on various supporting frameworks in skyscraper steel structures of 15, 20, 25, 30 and 35 stories. The impacts of a few parameters affecting the seismic execution, including sort of the propping framework, the tallness of the building and parallel load designs, were explored. The outcomes demonstrated that the distinctive supported edges performed well as far as story removal, between story float proportion, base shear and execution moment that contrasted and the opposing edge in skyscraper steel structures.

\section{Materials and Methods}

This includes utilizing Building models made in Revit for examination inside Revit and transfer to GBS for advance analysis. Autodesk Revit has a few Building Performance Analysis (BPA) features accessible. This would provide plan of what is accessible and then to have detailed look at the essentials requirement of running an energy simulation from within Revit. This will incorporate an introduction to the new 3D energy determine in Revit 2017, the programmed zoning highlight in Revit 2017.

The study considers the following points:

- To determine reduction in energy demand and its effect on Energy rate, especially the Cooling cost because of the geographical location,

- For reduced $\mathrm{CO}_{2}$ emission: Which directly influences on climate changes,

- To use more natural Resources to reduce $\mathrm{CO}_{2}$ emission, and

- Simulate a Net Zero Energy building using software and view the results.

\subsection{Method}

\subsubsection{Creating the Revit Model}

The initial step is to make the model. The ideal process is beginning with massing, rapidly considering the shape and orientation.

\subsubsection{Creating an In-Place Mass}

In this, we will make some basic mass structures, create mass floors, and after that construct plan perspectives to evaluate the outcomes. Subsequently, activate the Level 1 story design before beginning the activity. Irrespective of whether masses set up or in the Family Editor, and then ready to create floor faces (not the real floors) and select the mass and determine the floor levels as appeared in the left side of model utilizing the Mass Floors tool. Likewise, utilize masses to characterize external shades. The Revit projects must not have less than one mass with mass floors appointed to make a considerable Energy Analysis Model.

\subsubsection{Exterior Wall Area}

The net wall region (net wall area, subtract openings) of the model.

\subsubsection{Design Options}

Revit's Design Options highlight certain extent works for energy demonstrating the underlying plan stage. The Energy Analysis Model (EAM) is characterized by components in the Main Model in Figure 1(a) and the Primary plan shown in Figure 1(b).

\subsubsection{Rectangular Shape}

A rectangular shape structure of $100 \mathrm{~m}$ height with $4 \mathrm{~m}$ floor to floor clear distance is created as shown Figure 2.

- The opening on the each level is $40 \%$ according to its shape and dimension and position of windows and door for sun light and heating \& cooling of the building requirements, and

- Total gross Area of rectangular shape building is $41,250 \mathrm{~m}^{2}$ with 25 floors. The inter-storey height is considered as in $4 \mathrm{~m}$ floor to floor and Project Location is Chandigarh. 


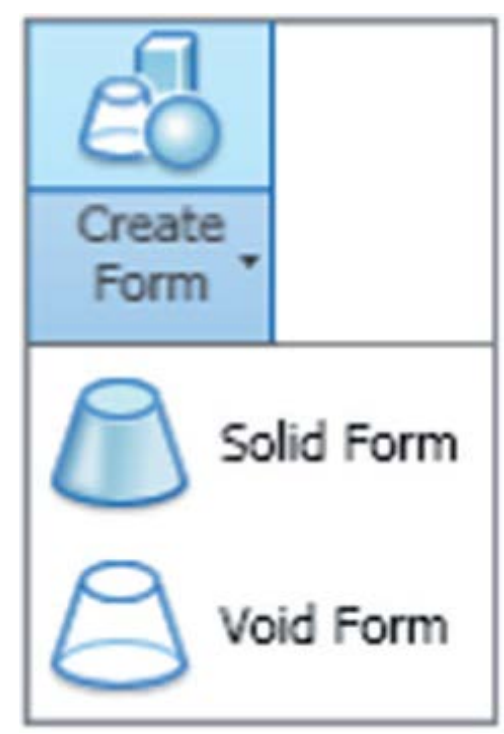

(a)

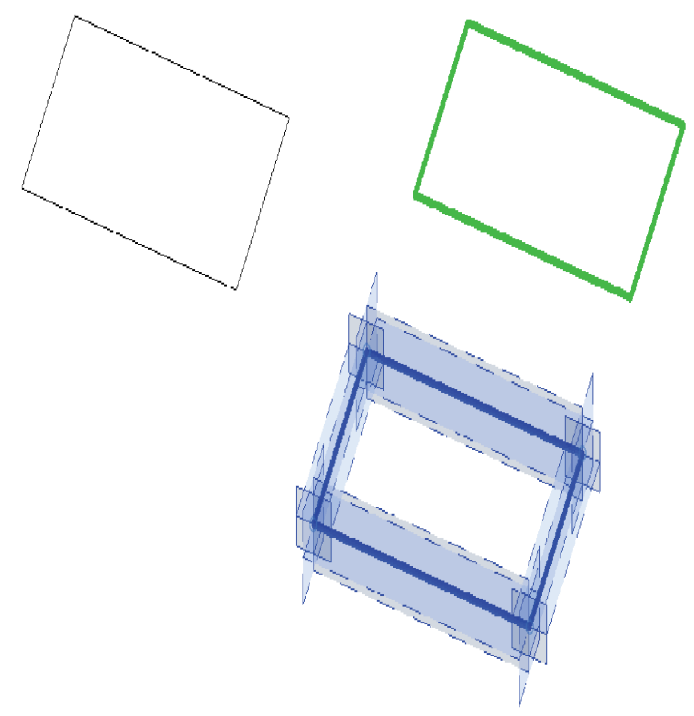

(b)

Figure 1. The main model and primary plan.

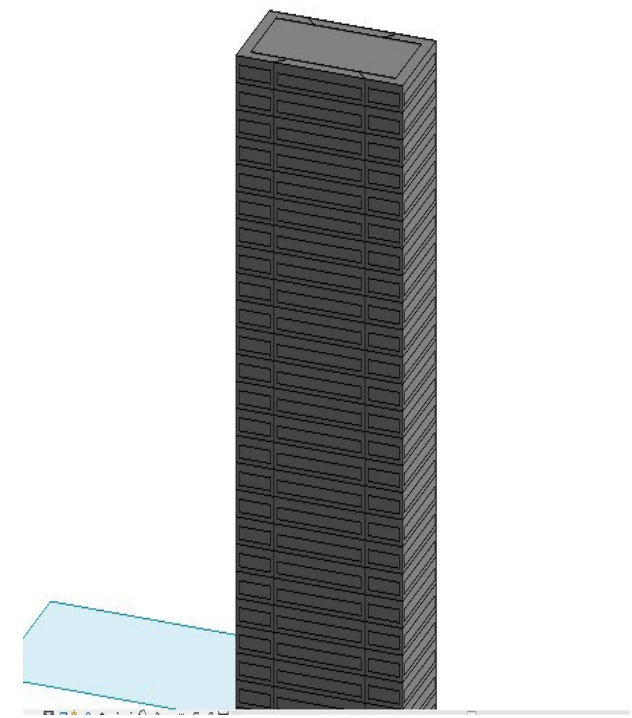

Figure 2. Rectangular 3-D VIEW.

\subsection{The Hexagonal}

The Hexagon taken in as simple as well as orientation based. It has same parameter as 25 meter each edge length with 100 meter height plan shape Figure 3.

\subsubsection{Project North}

It is usually based on the principal axis of the building model. All Drawing and detailing with Project North

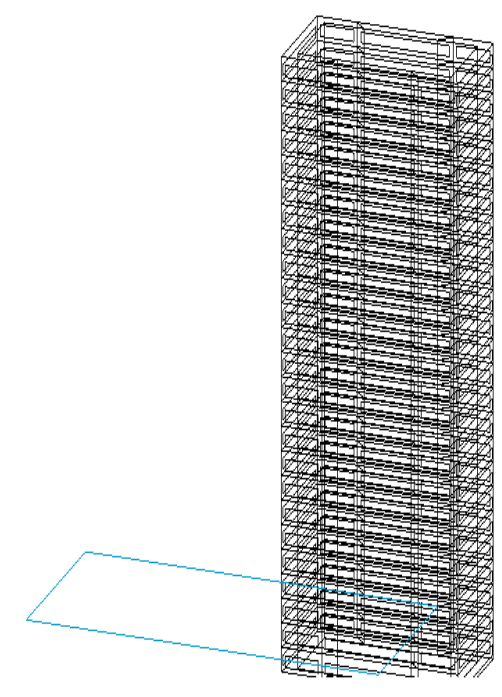

and True North aligned by the top of the drawing area, as specified by the survey point and the project base point in the site plan view.

\subsubsection{Rotating Project North}

In this entire model in plan views, changes the model's orientation to the top of the drawing area.It disturbs plan views whose Orientation properties are well-defined in 

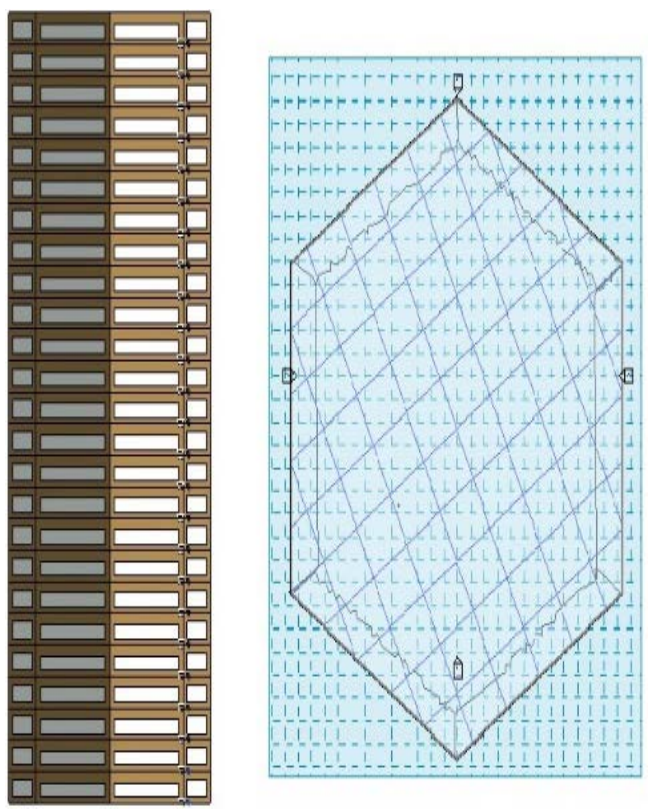

Figure 3. Hexagon 2D.
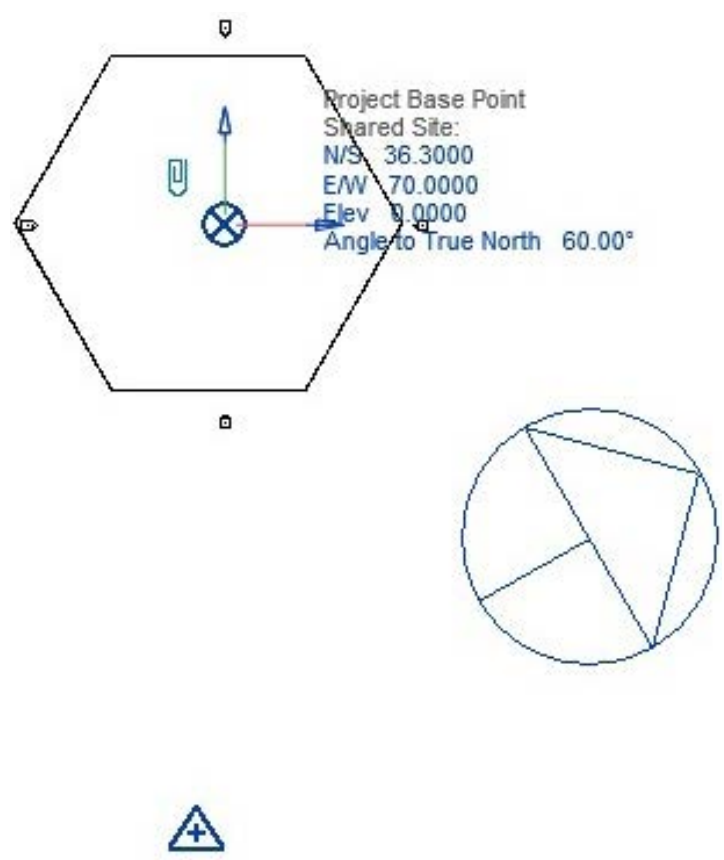

Figure 4. Orientation at 60 Degree.

Project North. It does not disturb the drafting views, or other types of views. In this the arrow represents the true north with respect to project north. Here building orientation is at 60 degree rotated in comparison of actual north location as shown in Figure 4 at 60 degree and in Figure 5 at 90 degree.

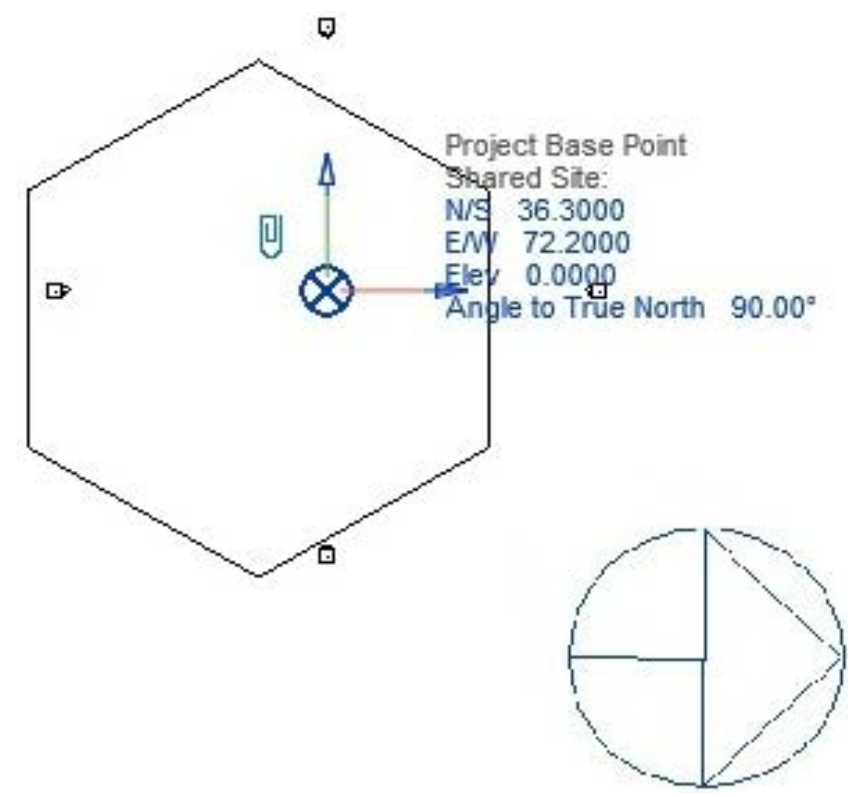

Figure 5. Orientation at 90 Degree.

\subsection{Cayan Tower}

This structure also has the same height and floor with same glazing area (40\%) on floor, only the width of floor vary due to its shape (Figure 6) with following specification:

- $\quad$ Rotation at 45 degree from centre \& 90 degree from top, and

- Consists of 25 floors with 4 meter floor to floor ratio.
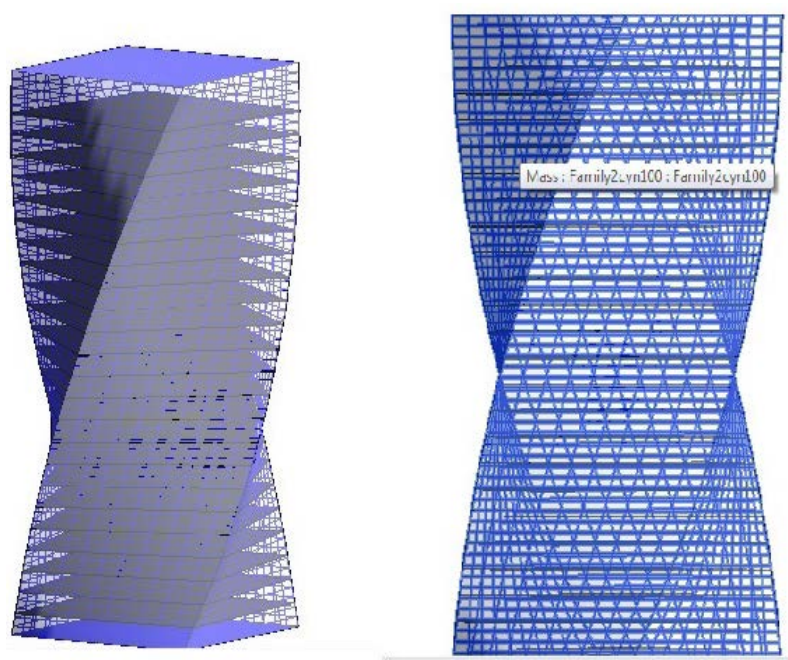

CAYAN TOWER UAE

Figure 6. 3-D modelling of cayan tower. 


\section{Results and Discussion}

The results contained here were developed by running simulations in Revit and Green building studio. Different Type settings were attempted on the construct and display and with respect to the Energy simulation model. The weather information, spatial information were obtained by the software. Other criteria like development material of outer components were adjusted to reduce the energy demand because of warming. Air conditioning was changed for various costs because of more effective result. Different changes connected to the base model to make a more sustainable plan and the result is displayed in the associated sections.

The results will be investigated on basis of:

- Energy utilize by PV,

- $\mathrm{CO}_{2}$ emission, and

- Energy cost.

\subsection{Rectangular Plan the Output}

\subsubsection{Electricity EUI}

The measure of electricity per use floor area; In case of rectangular the electricity EUI is $154 \mathrm{kwh} / \mathrm{sm} /$ year.

\subsubsection{Fuel EUI}

It is yearly fuel consumption per floor area; Fuel per floor is $17.5 \mathrm{kwh} / \mathrm{sm} / \mathrm{yr}$.
- In GBS, the result are converted to kWh using $1 \mathrm{MJ}=0.277778 \mathrm{kWh}$.

\subsubsection{Carbon Emission}

Carbon emission is calculated based on CARMA (carbon Monitoring for Action) as follows:

Electricity consumption +Fuel consumption-Roof PV Potential $=\mathrm{Net}^{\mathrm{CO}_{2}}$

Net $\mathrm{CO}_{2}=2344+158-141=2361$ metric ton $/$ year

\subsubsection{Calculation of Electricity in Each Month for Rectangular Plan (Table 1).}

Total $\mathrm{kWh}=1000$ Watts $\mathrm{x} 24 \mathrm{Hrs} \times 30$ Days $=720000$ watts/hour.

to convert it into Units, where $1 \mathrm{unit}$ is $=1 \mathrm{kWh}$.

So the total Consumed units: $720000 / 100(k=k i l o=1000)$. Total Units $=720$.

Cost per unit is 6.So total Cost or Electricity bill $=720$ x $6=4,320 \mathrm{INR}$

1 unit $=1 \mathrm{kWh}$. For $400 \mathrm{KWH}=400^{\star} 1000 \mathrm{watt}^{\star} 24 \mathrm{hrs}{ }^{\star} 30$ days $=2,88,000$ units.

\subsection{In Hexagonal}

The annual electricity use in hexagon of each month is given in Figure 7. For the month of August calculated as $600 \mathrm{kwh}$. So it determines the minimum cost for operational.

Table 1. Monthly consumption rectangular

\begin{tabular}{|c|c|c|}
\hline Monthly Consumption & Unit per month & Cost (INR) \\
\hline January Consumption & $400^{\star} 1000 \mathrm{watt}^{\star} 24 \mathrm{hrs}^{\star} 30$ day $=288000$ UNITS & $288000 * 6=17,28,000 \mathrm{INR}$ \\
\hline February Consumption & $440^{*} 720=316,800$ UNITS & $316800 * 6=19,00,800 \mathrm{INR}$ \\
\hline March Consumption & $520^{*} 720=374400$ UNITS & $374400^{*} 6=22,46,400 \mathrm{INR}$ \\
\hline April Consumption & $560 * 720=403200$ UNITS & $24,19,200 \mathrm{INR}$ \\
\hline May Consumption & $610^{\star} 720=439200$ UNITS & $26,35,200 \mathrm{INR}$ \\
\hline June Consumption & $600^{*} 720=4,32,000$ UNITS & $25,92,000 I N R$ \\
\hline July Consumption & $600^{\star} 720=4,32,000$ UNITS & $25,92,000 \mathrm{INR}$ \\
\hline August Consumption & $620^{*} 720=4,46,400$ UNITS & $26,78,400 \mathrm{INR}$ \\
\hline September Consumption & $550 * 720=396000$ UNITS & $23,76,000 \mathrm{INR}$ \\
\hline October Consumption & $580^{*} 720=417600$ UNITS & $25,05,600 \mathrm{INR}$ \\
\hline November Consumption & $480^{\star} 720=3,45,600$ UNITS & $20,73,600 \mathrm{INR}$ \\
\hline December Consumption & $410^{\star} 720=2,95,200$ UNITS & $17,71,200 \mathrm{INR}$ \\
\hline
\end{tabular}




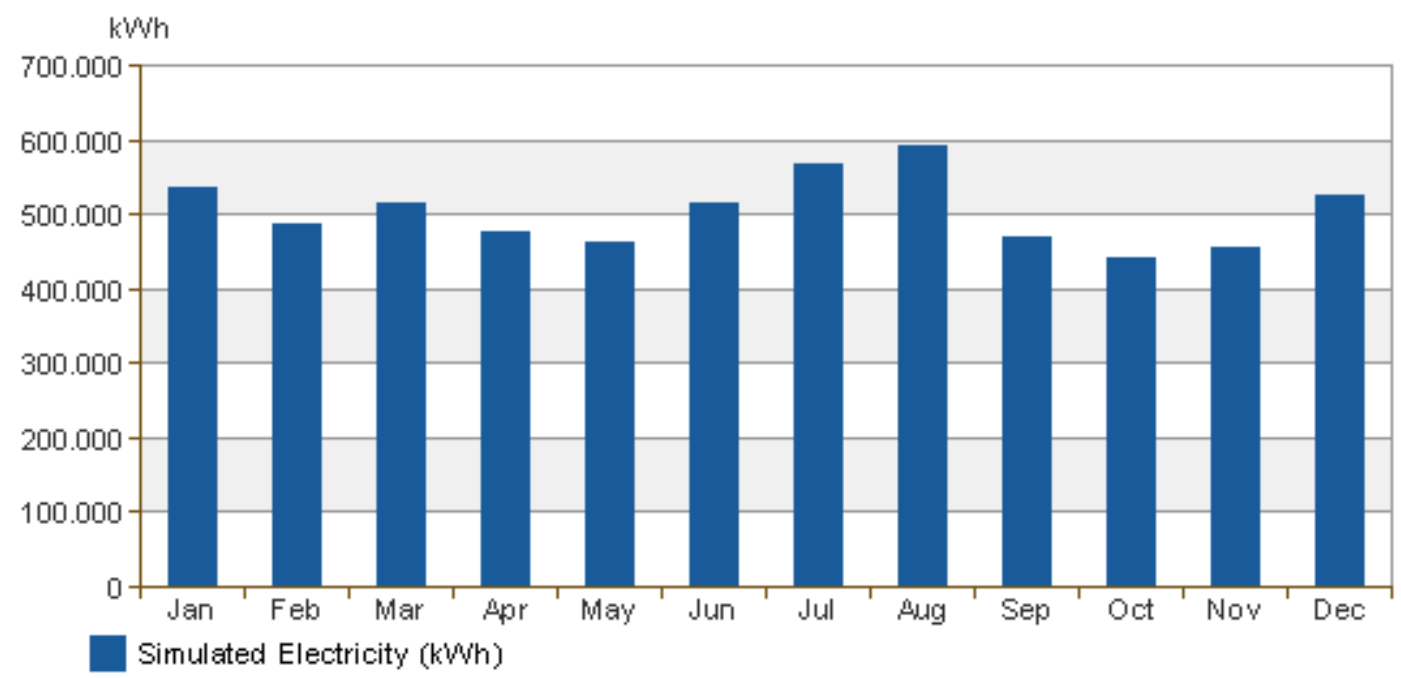

Figure 7. Monthly consumption data for 90 Degree.

\subsubsection{Annual Carbon Emissions}

At 90 degree

Carbon emission from electricity $=2344$

Carbon emission from fuel $=158$

From Roof $(\mathrm{PV})=-141$

Net CO2 $=2344+158-141=2361$ metric ton $/ \mathrm{yr}$

\subsubsection{Annual Carbon Emissions}

At 60 degree.

Carbon emission from electricity $=2268$

Carbon emission from fuel $=604$

From Roof $(\mathrm{PV})=-126$

Net $\mathrm{CO}_{2}=2344+158-141=2744$ metric ton $/ \mathrm{yr}$
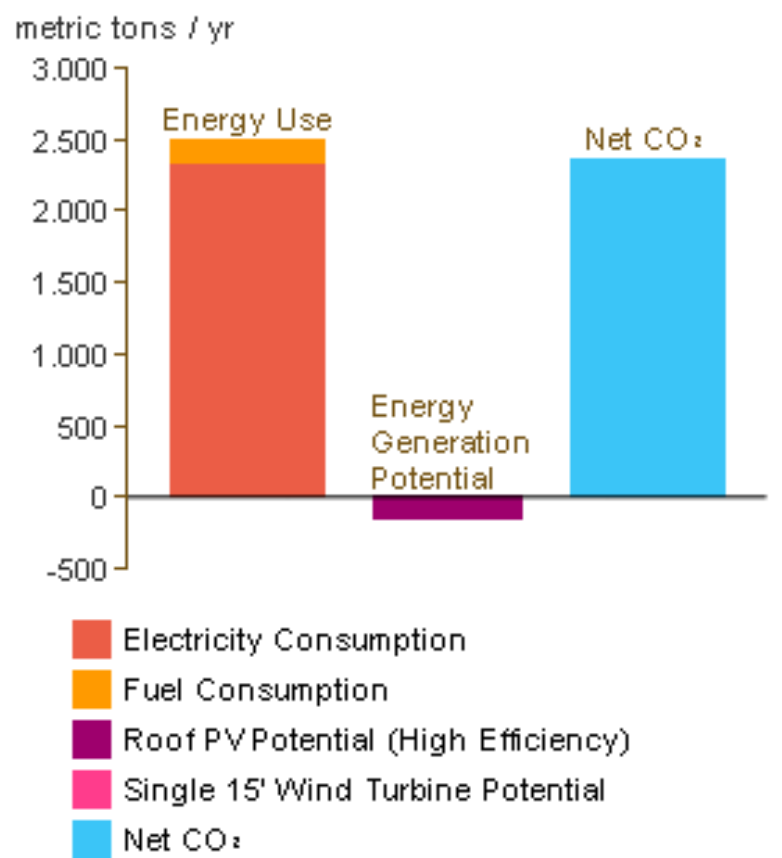

(metric tons / yr)

2,344

158

$-141$

$\frac{0}{2,361}$

Figure 8. Annual carbon emissions at $90^{\circ}$. 


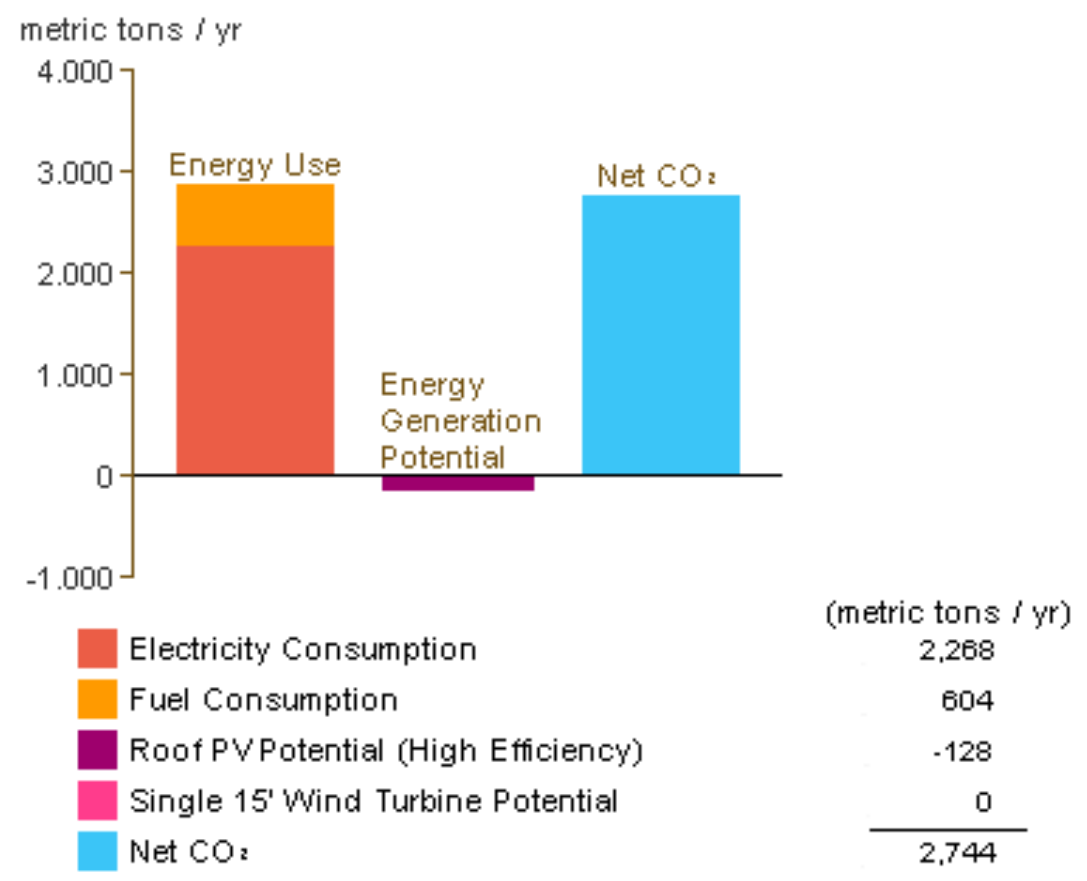

Figure 9. Annual carbon emissions $60^{\circ}$

The emission of carbon is much lower in hexagon at 90 degree rectangular as shown Figure 8 as it is 2361 metric ton/ year and the Figure 9 shows the carbon emission as much higher in 60 degree oriented high rise structure. Because the combustion of fuel resources are less and the natural heat and PV (photovoltaic) covers the maximum surfaces at 90 degree orientation. The solar PV maintains the requirements.

\subsection{CayanTower}

The floor area and Occupancy is very less and its energy consumption maximum the natural PV generation also less.
Comparison of the each 3 different model in Chandigarh in Table $2 \& 3$ (for life cycle up to 30 years energy use) the basic cost is used for calculation are:

\section{$1 \mathrm{USD}=65 \mathrm{INR}$}

$1 \mathrm{kWh}$ is equivalent to $3.6 \times 10^{6} \mathrm{~J}$ ( $3600 \mathrm{~kJ}$ or $3.6 \mathrm{MJ}$ )

Electricity Cost per unit ₹6 in Chandigarh

Occupancy per person in office 200 to 400 square feet. these are standard for any type of office building further the how many cabins, meeting rooms desire the capacity will vary.

Table 2. Comparison of result among 3 high rise in Chandigarh

\begin{tabular}{|l|l|l|l|}
\hline Features & CAYAN 100m & Hexagon 100m & Rectangular 100m \\
\hline Plan 3D-View & & & \\
\hline Floor Area & $37964 \mathrm{~m}^{2}$ & $40595 \mathrm{~m}^{2}$ & $41250 \mathrm{~m}^{2}$ \\
\hline Height & $100 \mathrm{~m}$ & $100 \mathrm{~m}$ & $100 \mathrm{~m}$ \\
\hline No of Floor & 25 & 25 & 25 \\
\hline Roof PV (high) & $417,151 \mathrm{kwh} / \mathrm{yr}$ & $461,204 \mathrm{kwh} / \mathrm{yr}$ & $430,187 \mathrm{kwh} / \mathrm{yr}$ \\
\hline Electrical EUI & $159 \mathrm{KWH} / \mathrm{SM} / \mathrm{YR}$ & $152 \mathrm{KWH} / \mathrm{SM} / \mathrm{YR}$ & $154 \mathrm{KWH} / \mathrm{SM} / \mathrm{YR}$ \\
\hline Fuel EUI & $80 \mathrm{MJ} / \mathrm{SM} / \mathrm{YR}$ & $72 \mathrm{MJ} / \mathrm{SM} / \mathrm{YR}$ & $63 \mathrm{MJ} / \mathrm{SM} / \mathrm{YR}$ \\
\hline People & 1519 & 1624 & 1650 \\
\hline
\end{tabular}


Table 3. Life cycle energy use/cost in 30 years life

\begin{tabular}{|l|l|l|l|}
\hline Features & CAYAN 100m & Hexagon 100m & 100m Rectangular \\
\hline Life Cycle Electrical use (kwh) & $157,650,450$ & $188,634,550$ & $190,461,840$ \\
\hline Cost (INR) $\{$ Electricity\} & $94,59,02,700$ & $1,13,18,07,300$ & $1,14,27,71,040$ \\
\hline Fuel use (MJ) & $89,386,083$ & $92,256,854$ & $78,390,933$ \\
\hline
\end{tabular}

In the above 3 different geometrical shapes, the Hexagonal building with 90 Degree orientation high-rise is best in terms of area, occupancy of people, and energy consumption (electrical and fuel), operational cost and carbon Emission as shown in Table 4.

\section{Solar Path Analysis}

In spite of the way that we understand that the sun rises in the east and sets in the west, as we aware that the sun does not rise absolutely east or sets definitely west. Rather

Table 4. Comparison between 2-different hexagonal

\begin{tabular}{|l|l|l|}
\hline & & \\
& & \\
& & \\
& &
\end{tabular}

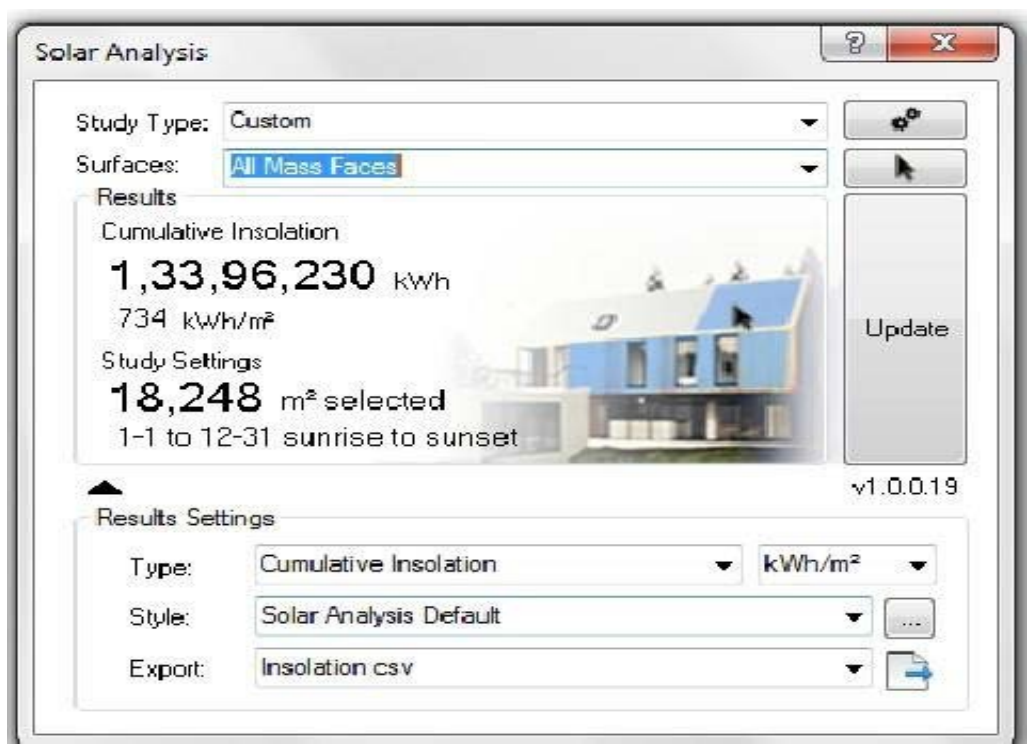

Figure 10. Energy produces by PV (yearly). 


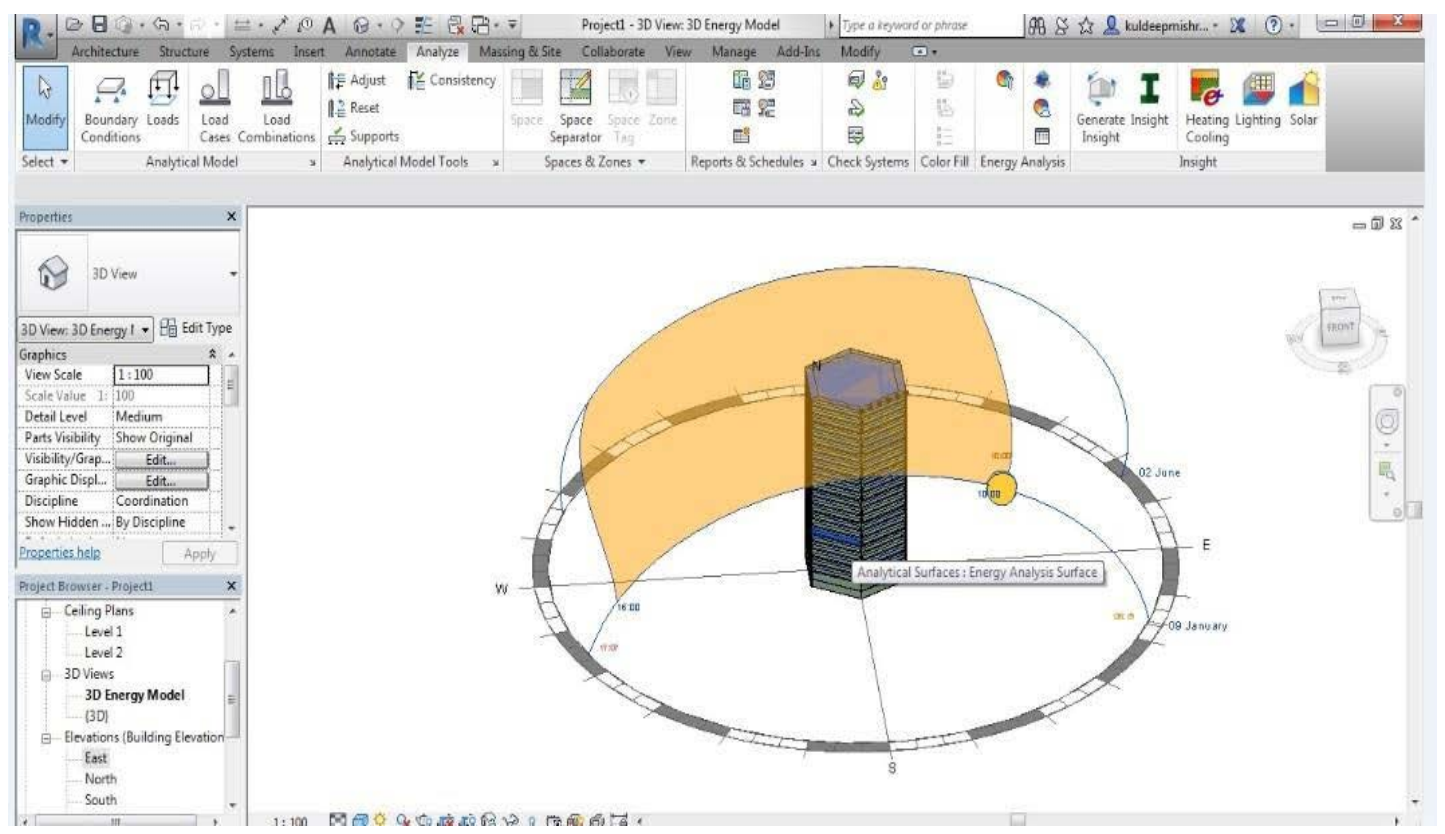

Figure 11. Sun path movement in January to June.

Table 5. Different Location in India

\begin{tabular}{|l|l|l|l|l|}
\hline Cities & Kolkata & Jaipur & Bhopal & Chennai \\
\hline Longitude \& Latitude & $22.5726^{\circ} \mathrm{N}, 88.3639^{\circ} \mathrm{E}$ & $26.9124^{\circ} \mathrm{N}, 75.7873^{\circ} \mathrm{E}$ & $23.2599^{\circ} \mathrm{N}, 77.4126^{\circ} \mathrm{E}$ & $13.0827^{\circ} \mathrm{N}, 80.2707^{\circ} \mathrm{E}$ \\
\hline Temperature (Degree Celsius) & Max.39,Min.10 & Max.45,Min.1 & Max.44,Min.6 & Max.38,Min.18 \\
\hline Electricity (EUI) (MJ/SM/YR) & 242 & 229 & 231 & 174 \\
\hline Fuel (EUI) (MJ/SM/YR) & 103 & 141 & 149 & 17 \\
\hline $\begin{array}{l}\text { Life cycle energy use/cost } \\
\text { (INR)up to 30 YR manually }\end{array}$ & $9,95,40,09,655$ & $12,83,45,20,865$ & $13,49,94,69,815$ & $2,63,63,34,065$ \\
\hline $\begin{array}{l}\text { Renewable Energy Potential } \\
\text { (medium PV) kwh/year }\end{array}$ & 276,120 & 254,790 & 266,227 & 276,120 \\
\hline Net CO2 (Metric Ton) & 5537 & 5268 & 3707 & 2517 \\
\hline Annual electricity use (KWH) & $98,39,821$ & $93,13,702$ & $93,78,058$ & $70,65,636$ \\
\hline Fuel use (mj) (annual) & $41,96,329$ & $57,22,079$ & $60,57,138$ & $6,99,753$ \\
\hline
\end{tabular}

the sun may rise north of east or further south of east, depending upon which part of the earth we are at observing. To understand where we stay on the earth, it is demonstrated by the latitude and longitude. So it indicates photovoltaic energy calculation as shown in Figure 10. The sun oriented Photovoltaic electricity covering the area of $18,248 \mathrm{~m}^{2}$ the total energy generates $1,33,96,230 \mathrm{kwh}$ in a year as shown Figure11. At the different Location of high rise building effects on different states of India we checked for the most preferred location in terms of cost of energy consumption as in Table 5.
As data presented in Figure 12, the maximum electricity and fuel use in Kolkata, but life cycle cost is more in Bhopal, because of the renewable energy generation in Bhopal is less $(266,227)$ as compared to Kolkata and Chennai.

\section{Conclusions}

The analyses of structure include the most effective way to utilise the energy and solar analyses, massing in building, orientation. The most effective is cost saving calculation 


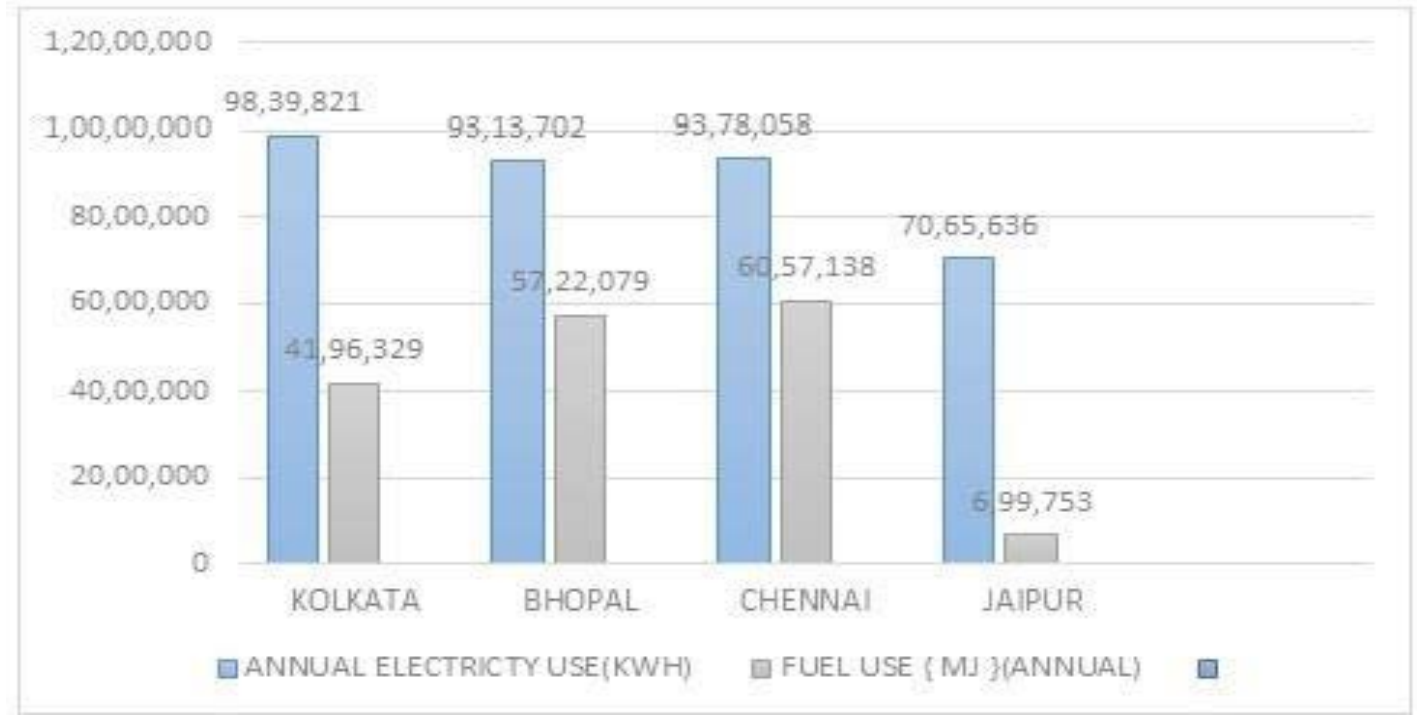

Figure 12. Annual electricity and fuel use.

and time management as compared to other traditional methods.It is reasoned that BIM models are exceptionally valuable and proficient in calculating the building energy execution.

- In the above studies, among three model geometry, the Hexagonal shape with 90 oriented gives the most effective results in term of Space, occupancy and renewable energy efficient and emitting less carbon or GHG to the environment,

- In the second parameter, the effective orientation of hexagon has obtained at the 90 degree is preferred With respect to project north to true north,

- The most suitable city is Chennai and Bhopal, according to most energy consumption parameters as operation cost is economical, and

- The estimated simulated results and real energy utilization gives a superior understanding and a reflection of the real execution.

\section{References}

1. Peng C, Huang Y, Wu Z. Building-Integrated Photo-Voltaics (BIPV) in architectural design in China, Energy and Buildings. 2011; 43(12):3592-98. https://doi.org/10.1016/j. enbuild.2011.09.032.

2. Son JW, Seo HC, Hong WH. A Study on the characteristics of energy consumption in University Dormitory, Information. Japan. 2015; 18(6):2825-30. https://doi. org/10.14257/astl.2015.89.07.

3. Building Energy Performance Analysis of an Academic Building Using IFC BIM-Based Methodology. Date accessed: 26/10/2012. https://oaktrust.library.tamu.edu/ bitstream/handle/1969.1/148948/ESL-IC-12-10-53a. pdf? sequence $=3$ \&isAllowed $=y$.

4. Patil DM, Sangl KK. Seismic behaviour of different bracing systems in high rise 2-D steel buildings, Structures. 2015; 3:282-305. https://doi.org/10.1016/j.istruc.2015.06.004.

5. Building Information Modeling (BIM) in Structural Engineering. Date accessed: 2017. https://www.asce.org/ templates/conferences-events-event-detail.aspx?id=8814. 